\title{
Mutation affecting the proximal promoter of Endoglin as the origin of hereditary hemorrhagic telangiectasia type 1
}

Virginia Albiñana', Ma Paz Zafra', Jorge Colau', Roberto Zarrabeitia², Lucia Recio-Poveda', Leticia Olavarrieta Julián Pérez-Pérez ${ }^{3}$ and Luisa M. Botella ${ }^{1 *}$

\begin{abstract}
Background: Hereditary hemorrhagic telangiectasia (HHT) is a vascular multi-organ system disorder. Its diagnostic criteria include epistaxis, telangiectases in mucocutaneous sites, arteriovenous malformations (AVMs), and familial inheritance. HHT is transmitted as an autosomal dominant condition, caused in $85 \%$ of cases by mutations in either Endoglin (ENG) or Activin receptor-like kinase (ACVRL1/ACVRL1/ALK1) genes. Pathogenic mutations have been described in exons, splice junctions and, in a few cases with ENG mutations, in the proximal promoter, which creates a new ATG start site. However, no mutations affecting transcription regulation have been described to date in $\mathrm{HHT}$, and this type of mutation is rarely identified in the literature on rare diseases.
\end{abstract}

Methods: Sequencing data from a family with HHT lead to single nucleotide change, c.-58G > A. The functionality and pathogenicity of this change was analyzed by in vitro mutagenesis, quantitative PCR and Gel shift assay. Student $t$ test was used for statistical significance.

Results: A single nucleotide change, c.-58G > A, in the proximal ENG promoter co-segregated with HHT clinical features in an HHT family. This mutation was present in the proband and in 2 other symptomatic members, whereas 2 asymptomatic relatives did not harbor the mutation. Analysis of RNA from activated monocytes from the probands and the healthy brother revealed reduced ENG mRNA expression in the HHT patient $(p=0.005)$. Sitedirected mutagenesis of the ENG promoter resulted in a three-fold decrease in luciferase activity of the mutant c.$58 \mathrm{~A}$ allele compared to wild type $(p=0.005)$. Finally, gel shift assay identified a DNA-protein specific complex.

Conclusions: The novel ENG c.-58G > A substitution in the ENG promoter co-segregates with HHT symptoms in a family and appears to affect the transcriptional regulation of the gene, resulting in reduced ENG expression. ENG c.58G > A may therefore be a pathogenic HHT mutation leading to haploinsufficiency of Endoglin and HHT symptoms. To the best of our knowledge, this is the first report of a pathogenic mutation in HHT involving the binding site for a transcription factor in the promoter of ENG.

Keywords: Hereditary hemorrhagic telangiectasia (HHT), Rare disease, Endoglin promoter, Transcription regulation

\footnotetext{
* Correspondence: cibluisa@cib.csic.es

${ }^{1}$ Centro de Investigaciones Biológicas, Consejo Superior de Investigaciones

Científicas (CSIC), and Centro de Investigación Biomédica en Red de

Enfermedades Raras (CIBERER), Ramiro de Maeztu 9, Madrid 28040, Spain

Full list of author information is available at the end of the article
}

(c) The Author(s). 2017 Open Access This article is distributed under the terms of the Creative Commons Attribution 4.0 International License (http://creativecommons.org/licenses/by/4.0/), which permits unrestricted use, distribution, and reproduction in any medium, provided you give appropriate credit to the original author(s) and the source, provide a link to the Creative Commons license, and indicate if changes were made. The Creative Commons Public Domain Dedication waiver (http://creativecommons.org/publicdomain/zero/1.0/) applies to the data made available in this article, unless otherwise stated. 


\section{Background}

Hereditary hemorrhagic telangiectasia (HHT), also known as Rendu-Osler-Weber syndrome [1, 2], is a vascular disorder with autosomal dominant inheritance. The latest epidemiological data reveal that HHT affects approximately 1 in every 5,000 individuals [2]. The clinical symptoms, known as the Curaçao criteria [3], diagnose an HHT patient when at least 3 of the 4 criteria are present: epistaxis (nose bleeds), mucocutaneous telangiectases, arteriovenous malformations (AVMs) affecting mostly the lung, liver and brain, and an autosomal dominant pattern of familial inheritance. Hereditary Hemorrhagic Telangiectasia is caused by mutations in at least one of the 3 genes involved in the transforming growth factor-beta (TGF- $\beta$ ) signaling pathway [4]. Endoglin (ENG, chromosome 9q34), Activin A receptor type II-like 1 (ACVRL1/ACVRL1/ALK1, chromosome 12q13), and MADH4/SMAD4 (chromosome 18q21) mutations cause HHT1 (OMIM 187300), HHT2 (OMIM 600376), and the combined Juvenile Polyposis/HHT (JP/HHT) syndrome (OMIM 175050), respectively [5-7]. There are two further unidentified genes that can cause HHT: HHT 3 between 141.9 and 146.4 Mb on chromosome $5 \mathrm{q}$ and HHT4 on chromosome 7p between D7S2252 and D7S510.130 [8, 9]. Recently, BMP9 mutations have been shown to give rise to HHT5, although the contribution of BMP9 mutations to HHT is estimated to be very low $(<1 \%)[10]$.

The genes that are mutated in HHT encode proteins that mediate signaling by the TGF- $\beta$ superfamily. In the TGF- $\beta$ signaling cascade, the type II receptor cooperatively recruits and transphosphorylates the type I receptor by direct contact with T $\beta R I$ [11]. In endothelial cells, upon ligand binding, T $\beta$ RII can associate with two different TGF- $\beta$ type I receptors: ALK-5 or ALK-1 [12]. Endoglin is an auxiliary receptor that modulates both complexes in opposite manners. Thus, whereas Endoglin promotes signaling through ALK-1, it inhibits the ALK-5 pathway [13]. In turn, ALK-1 and ALK-5 activate distinct $\mathrm{R}$-Smad pathways, resulting in opposing endothelial cell responses in proliferation, migration, and pro- or antiangiogenic gene expression.

More than 600 different mutations have been identified in ENG and ACVRL1 in HHT families (HHT mutation database; http://www.arup.utah.edu/database/hht/).

These mutations range from single base-pair changes to large deletions of multiple exons and are of all types, including substitutions, duplications, and deletions. There are no common mutation "hotspots" in either gene, and mutations have been observed across all coding regions.

Considering substitutions, missense mutations are the most common type observed in ENG and ACVRL1, and mutations have been identified in all exons of both genes, including exon/intron boundaries and splice-site junctions. However, the proportion of mutations causing a frameshift or stop codon in the protein (i.e., indels and non-sense mutations) are more frequent in ENG than in ACVRL1 [14-16].

Although many ENG mutations have been identified in the extracellular region of the protein, which is the largest part of the protein, very few mutations have been identified in the transmembrane and cytoplasmic domains [16]. Large deletions or duplications of one or more exons account for $6-10 \%$ of all ENG and ACVRL1 mutations [17]. Large deletions in the Endoglin gene, encompassing promoter and several exons or the whole gene, have previously been described by our group [18]. Mutations in the 5'UTR region of ENG (c.-9G > A and c. $-127 \mathrm{C}>\mathrm{T}$ ) have also been found to cause HHT. They were determined to be pathogenic by creating an alternative, out-of-frame transcription start codon, but the possibility of altering binding sites for transcriptional factors could not be discarded. Interestingly, (c.-9G > A) is a hypomorphic variant that can be detected in a homozygous state.

These mutations emphasize the need for including the ENG 5'UTR region in routine molecular diagnostic testing for HHT [19]. However, to date, few mutations affecting a site in the promoter of either Endoglin or ACVRL1/ALK1 have been reported. A mutation in the regulatory site present in intron 6 $($ c. $772+27 \mathrm{G}>\mathrm{C})$ of $A C V R L 1$ has been described in an HHT2 Chinese family [20].

Although the $5^{\prime}$-flanking region of the Endoglin gene lacks consensus TATA and CAAT boxes, it contains $\mathrm{GC}$-rich regions and consensus motifs for $\mathrm{Sp} 1$, ets, GATA, and TGF- $\beta$ (Smads), and estrogen-responsive elements. The upstream $-400 /+341$ region is able to display tissue-specific activity in human endothelial cells. Analysis of various deletion constructs demonstrated the existence of a basal promoter region within the $-81 /+350$ fragment [21].

In the present study, we describe, for the first time, a pathogenic mutation that causes HHT type 1 by affecting a single base pair nucleotide change at the c.-58G > A position of the proximal promoter of Endoglin, which is embedded in this basal promoter region.

\section{Methods}

\section{Patient samples}

Blood samples were collected at different hospitals and sent to our institute. They were received on the day after blood extraction. Informed consent was obtained from each patient. HHT diagnosis was based on the clinical Curaçao criteria [3]. Each sample was anonymously treated and identified with a code number. 


\section{Ethics statement request}

The human blood samples and clinical data reported in this manuscript were obtained with prior approval from the appropriate ethics committees of the CSIC for the research conducted in the Centro de Investigaciones Biológicas (CIB, Madrid), the CEIC (Clinical Research Ethics Committee) of the Cantabrian Health Service for patients at the Hospital of Sierrallana (Torrelavega, Santander, Cantabria), and the Medical Genetics department of the Hospital Valdecilla (Santander, Cantabria). Research was carried out in compliance with the Helsinki Declaration (http:// www.wma.net/en/30publications/10policies/b3/index.html), keeping the results strictly confidential, with numerical codes for patient identification. http://www.wma.net/en/ 30publications/10policies/b3/index.html.

\section{DNA extraction and mutation analysis}

Genomic DNA was extracted from peripheral blood, using the QIAamp kit (Qiagen, Gmbh, Germany). The coding exons from Endoglin, the 9 translated exons from $A C V R L K 1 / A L K 1$, including exon 1 (transcribed but not translated), the exon intron boundaries (50 bp), and the proximal promoters of both genes were amplified by PCR and then sequenced using specific primers. MLPA was also performed for both genes to detect any changes in copy number. The primer sequences and PCR conditions have already been reported [4, 14]. PCR products, which were excised and cleaned from the gel (Millipore, Germany), were sequenced in forward and reverse orientation on an Applied Biosystems sequencer using the dye terminator sequencing kit according to the manufacturer's instructions. Sequences were compared with the following references for ACVRL1/ALK1: OMIM 601284 Gene ID: 94; Genomic ID: NG_009549.1; c-DNA ID: NM_000020.2; and Protein ID: NP_000011. For ENG, the references were OMIM 131195 Gene ID: 2022; Genomic ID: NG_009551.1; c-DNA ID: NM_001114753.1; and Protein ID: NP_001108225.12. The following database was used for HHT: http://arup.utah.edu/database/ $\mathrm{HHT} /$. Next, if no changes were found in the DNA sequence comparisons, MLPA [22] was performed according to the manufacturer's instructions using the P093 Salsa MLPA HHT/PPH1 probe set (MRC-Holland, Amsterdam, The Netherlands). DNA sequences and MLPA analyses were performed by Secugen S.L (Madrid, Spain). In the index case analyzed in this manuscript, only a change G > A, in position -58 bp of Endoglin promoter was observed; it was considered a variation of the gene and had an unknown effect (VUS).

\section{Site-directed mutagenesis}

Site-directed mutagenesis was carried out from a construct encompassing $350 \mathrm{bp}$ upstream of the transcription initiation start of ENG, including a 150-bp transcribed untranslated region before the codon start with the luciferase reporter gene in the pXP2 vector (-350/+150 ENG pXP2). Mutagenesis was performed using the Quick Change Site-Directed Mutagenesis kit from Agilent Technologies, according to the manufacturer's instructions. These procedures were followed by DpnI digestion to eliminate the original wild type DNA template. Oligonucleotides used for the mutagenesis were: $E N G$-58Mut:

Fwd: 5' - CCACAGCCCTGCCACTGGACA-3' Rev: 5'-TGTCCAGTGGCAGGGCTGTGG-3'

\section{Cell culture}

Human microvasculature endothelial cells, HMEC-1, were grown on $0.2 \%$ gelatin (Sigma-Aldrich) in PBScoated plates in MCDB-131 medium (Gibco) supplemented with 10\% FCS (Gibco), $1 \mathrm{ng} / \mathrm{ml}$ of EGF and $1 \mu \mathrm{g} / \mathrm{ml}$ of hydrocortisone (Sigma), $2 \mathrm{mM} \mathrm{L}$-glutamine (Gibco) and $100 \mathrm{U} / \mathrm{ml}$ of penicillin and streptomycin (Gibco).

\section{Transfections and luciferase assays}

Superfect ${ }^{\ominus}$ Transfection Reagent (Qiagen), was used for transient transfection according to the manufacturer's instructions. A total of $1 \mu \mathrm{g}$ from Luciferase Plasmid Reporters DNA [either wild type or mutated $(-350 /+150$ ENG pXP2)] and $20 \mathrm{ng}$ of pSV40- $\beta$ gal reporter plasmid (for transfection normalization) were incubated in OptiMEM (Gibco) with Superfect for $15 \mathrm{~min}$ at room temperature. The DNA-transfection reagent complexes were added to cells that were $80 \%$ confluent in P-24 wells. Transfection was allowed to proceed for $24 \mathrm{~h}$ at $37^{\circ} \mathrm{C}$ and $5 \% \mathrm{CO}_{2}$.

Cells were lysed in $1 \times$ lysis buffer from Promega. Relative units of luciferase (Promega luciferase reagent) were measured in a Glomax luminometer (Promega), and $\beta$ galactosidase units as measured by Galacto-light (Tropix) were used to normalize transfection efficiency. Each condition was repeated in triplicate. Treatments with TGF- $\beta 1$ (Preprotech) proceeded for $24 \mathrm{~h}$ with $10 \mathrm{ng} / \mathrm{ml}$. The control reporters of TGF- $\beta$, CAGA-luc, and BREluc were used in parallel as reporter controls of the TGF- $\beta$ response.

\section{RNA gene expression Isolation of MNCs, culture and RNA extraction}

From $5 \mathrm{ml}$ samples of peripheral blood from patients, the total fraction of MNCs (mononuclear cells) was isolated in a Ficoll gradient (Lymphocyte Separation Medium, Lonza). The MNC fraction was plated and cultured for $24 \mathrm{~h}$ in DMEM medium containing 10\% fetal bovine serum (FBS, Gibco). Total RNA from these activated MNCs was isolated using the NucleoSpin RNA purification kit from Macherey-Nagel (GmbH\&Co). 


\section{Quantitative RT-PCR}

For quantitative analysis of ACVRL1/ALK1 and ENG transcripts, total RNA was reverse-transcribed using the Reverse Transcriptase AMV cDNA Synthesis kit (Roche). The resulting cDNA was used as a template for real-time PCR performed using the SYBR Green PCR system (BioRad), with the following primers. ACVRL1/ ALK1: Fwd 5'-ATCTGAGCAGGGCGACAGC-3' and Rev 5' -ACTCCCTGTGGTGCAGTCA-3'; ENG Fwd 5' GCCCCGAGAGGTGCTTCT- 3 ' and Rev 5' ${ }^{\prime}$-TGCAGGAAGACACTGCTGTTTAC-3'. As an internal control, mRNA levels of $18 \mathrm{~S}$ were measured using these primers: Fwd 5' -CTCAACACGGGAAACCTCAC-3' and Rev 5' CGCTCCACCAACTAAGAACG-3'. Amplicons were detected using an iQ5 system (BioRad). Each experiment was performed in triplicates.

\section{Gel shift assay (EMSA) of proximal ENG mobility}

Nuclear extracts from confluent HMEC-1 cultures were obtained using a Nuclear Extract kit (Active Motif). The amount of protein was determined by the Bradford technique (Bio-Rad), and $10 \mu \mathrm{g}$ of total nuclear extract was used for incubation with the $5^{\prime}$ biotinylated oligonucleotide probe from Sigma Aldrich. Complementary oligonucleotides encompassing the -69 to -56 region of Endoglin promoter were annealed by heating $95{ }^{\circ} \mathrm{C}$ for 3 min, slowly cooling down to RT, and then incubating overnight at $4{ }^{\circ} \mathrm{C}$.

Biotinylated wt fwd -69/-56 5'- GGTGCCCGCCCGCAGCCCTGCCAC -3' Biotinylated wt rev -69/-56 5'- GTGGCAGGGCTGCGGGCGGGCACC -3'

The gel shift assay was carried out following the protocol of Gelshift ${ }^{\text {tw }}$ Chemiluminescent EMSA. Briefly, $20 \mathrm{ng}$ annealed probe was incubated with $10 \mu \mathrm{g}$ nuclear extract in the presence of $2 \mu \mathrm{g}$ of polydI-dC as non-specific competitor. Specific competition assays occurred with an excess (100-fold) of wt cold unlabeled annealed probe and the same amount of mutated cold unlabeled probe. Protein-DNA binding was allowed to proceed for $30 \mathrm{~min}$ at $4{ }^{\circ} \mathrm{C}$; then, samples with loading buffer were loaded in a $6 \%$ nondenaturing polyacrylamide gel in $0.5 \times \mathrm{TBE}$ and electrophoresed for $1 \mathrm{~h}$ at $4{ }^{\circ} \mathrm{C}$ and $150 \mathrm{~V}$. Next, the DNA-protein complexes and free probe were transferred to a nylon membrane by electroblotting. DNAprotein complexes were crosslinked by UV to the nylon membrane. The membrane was processed by blocking and was then incubated with the streptavidin-HRP conjugate for $30 \mathrm{~min}$. After being washed, the membrane was developed by the Super signal chemiluminescent Kit (Thermo-Scientific), according to the manufacturer instructions, and visualized with a Molecular Imager, Chemi-Doc.

\section{Statistics}

Data were subject to statistical analysis, and the results are shown as the mean \pm SD. Differences in mean values were analyzed using Student's $t$-test. In the figures, the statistically significant values are marked with asterisks $\left(" p<0.05 ;{ }^{* * *} p<0.01\right.$; and $\left.{ }^{* * * *} p<0.005\right)$.

\section{Results}

\section{Correlation between the presence of deletions in ENG} and clinical phenotype

DNA from a patient presenting epistaxis, gastric bleeding, telangiectasia and liver arteriovenous malformations was referred to our laboratory for genetic diagnosis after a clinical diagnosis of HHT was presented. After sequencing all exons, intron boundaries, and proximal promoter regions of ACVRL1/ALK1 and ENG and the MLPA of both genes, we could not find any mutations in the DNA. Only a change, $\mathrm{G}>\mathrm{A}$, in position $-58 \mathrm{bp}$ of Endoglin promoter was observed, and it was considered to be a variation of the gene with an unknown effect.

To determine whether the change could be the mutation causing HHT symptoms, 4 direct relatives of the index case were sequenced. The c.-58 G > A change was identified in two of them, and those two presented epistaxis and telangiectasia, whereas the other two relatives had no apparent clinical symptoms (epistaxis or telangiectasia in either adult). The phenotype-genotype correlation between led us to consider that the change could be pathogenic (Fig. 1). Clinically, the index case for HHT (I-1) (Fig. 1) was 79 years old and suffered from frequent epistaxis, exhibited many telangiectases on the face and hands and had arteriovenous malformations in the liver and gastric bleeding; therefore, it could not be considered a "mild" phenotype. Patient II-2 (Fig. 1) was a 45-year-old male who suffered from frequent epistaxis and had several telangiectases on the face and mucosa. No screening for AVMs occurred. The III-3 proband was 19 years old and had mild epistaxis and few telangiectases on the lips and fingertips.

\section{Site-directed mutagenesis of Endoglin proximal promoter and transfection}

To assess whether an Endoglin c.-58 bp G > A change could affect endoglin transcription, we performed sitedirected mutagenesis on an Endoglin promoter pCD105 $(-450 /+350)$ with a pXP2 luciferase reporter [23].

HMEC-1 cells were transfected with either the wild type or mutated sequence of the endoglin promoter. To control cell transfection, the pSV40-ßgal reporter plasmid was also co-transfected. At the same time, HMEC-1 
A

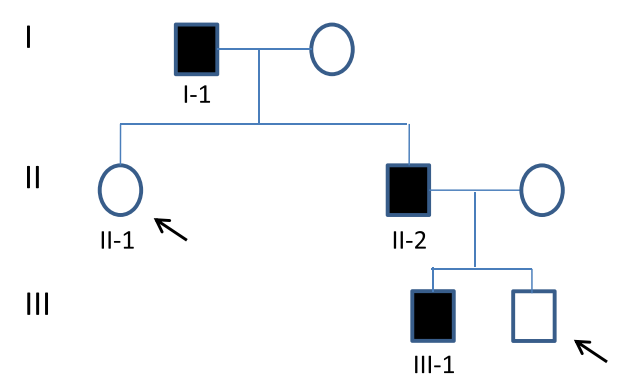

B

$\begin{array}{lllll}\text { Patient } & \text { Epistaxis E } & \text { Telangiectasia T } & \text { AVM } & \text { GB } \\ \text { I-1 } & \text { E } & \text { T } & \text { Liver } & \text { Yes } \\ \text { II-2 } & \text { E } & \text { T } & \text { No } & \text { No } \\ \text { III-3 } & \text { E } & \text { T } & \text { No } & \text { No }\end{array}$

C

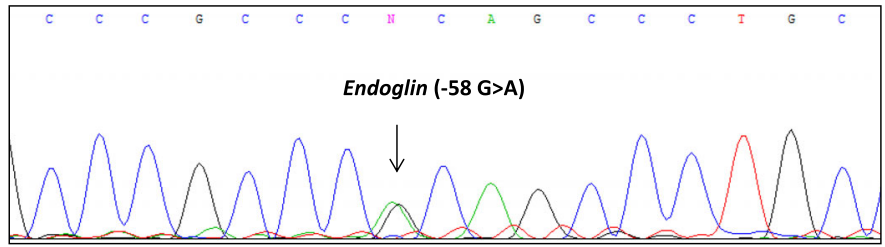

Fig. 1 a Schematic representation of the family tree with the distribution of HHT and normal relatives. b Clinical diagnostic criteria of the affected relatives. c Mutated sequence corresponding to this particular HHT family, showing the nucleotide substitution c.-58 G > A at the proximal promoter of Endoglin. Arrows point to the two unaffected individuals, who were also sequenced

cells were incubated in the presence or absence of $10 \mathrm{ng} / \mathrm{ml}$ of TGF- $\beta 1$ for $24 \mathrm{~h}$.

As shown in Fig. 2, the wild type endoglin promoter had 3-fold more luciferase activity than did the mutated promoter (c.-58 G > A). This difference was statistically

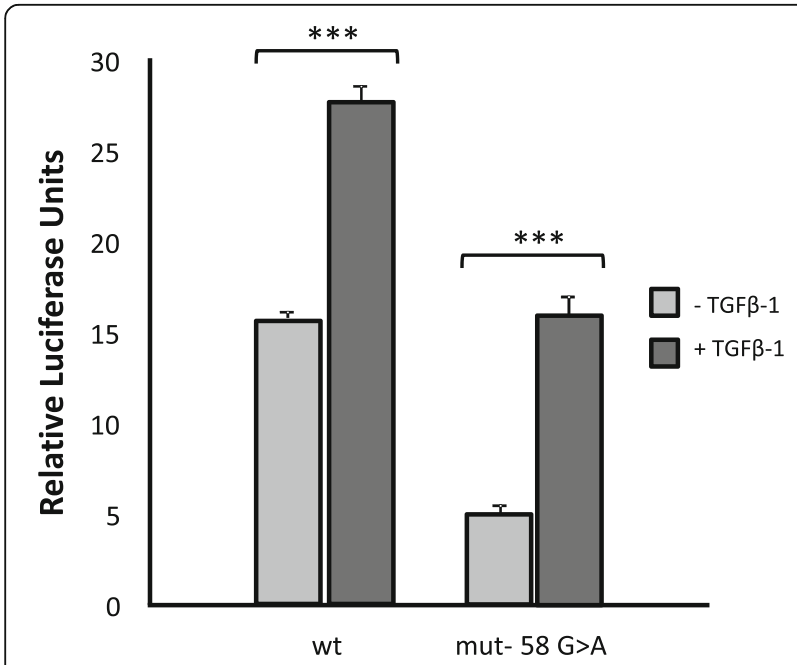

Fig. 2 Histograms representing the relative luciferase activity of wild type and mutated Endoglin promoter reporters after transfection into endothelial HMEC-1 cells. Site-directed mutagenesis was performed on the wild type promoter/reporter plasmid (350/+350 CD105 pXP2) of Endoglin. The effect of TGF- $\beta$ treatment is also shown significant, $p<0.005$. TGF- $\beta$ treatment upregulated both the wild type and mutated promoters; therefore, the mutation does not seem to involve a TGF- $\beta$ responsive element.

However, there was significantly more relative upregulation $(p<0.05)$ in the wild type than in the mutant after TGF- $\beta$ treatment.

\section{RNA endoglin expression of HHT and wild type monocytes activated in vitro}

Monocytes do not express significant levels of Endoglin [24]. However, the expression of Endoglin is triggered during the process of monocyte activation and transition to macrophage.

Because haploinsufficiency is the mechanism underlying HHT [2], and the (c.-58 G > A) in Endoglin promoter seemed to reduce, at least in vitro, the promoter activity in a reporter (Fig. 2), we decided to assess activated monocytes from $1 \mathrm{HHT}$ patient and his healthy brother, evaluating Endoglin expression in both patients side by side. In the case of the Endoglin RNA from the HHT patient, activated monocytes expressed significantly less Endoglin and ACVRL1/ALK1 compared to the healthy donor $(p<0.005)$ (Fig. 3). Figure 3 shows the relative expression of ENG and ACVRL1/ALK1 of the affected patient compared to the healthy sibling in activated monocytes. The amount of ENG RNA in the wild 


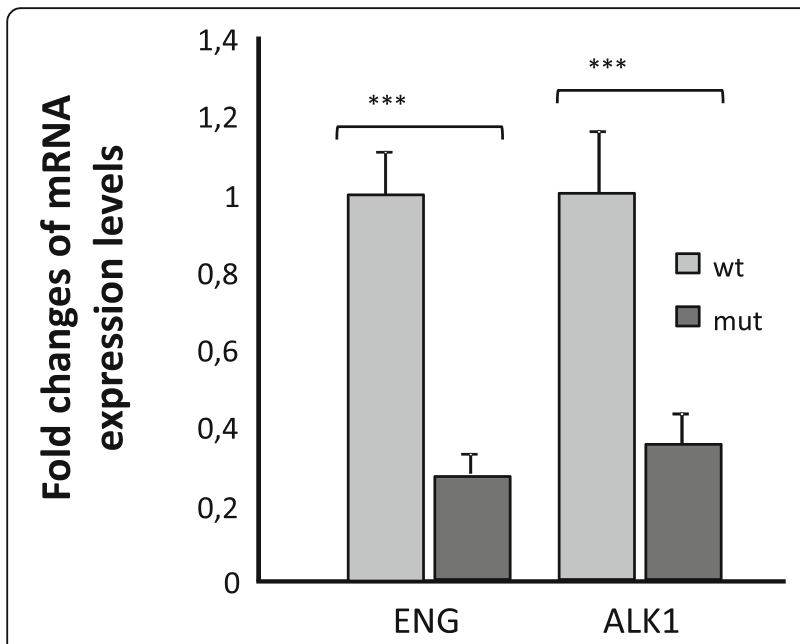

Fig. 3 Results of RT quantitative PCR showing the RNA transcription levels of Endoglin and ACVRL1/ALK1 genes of activated monocytes from a HHT patient compared with his control brother. The results are compared to the endogenous control 185 . The $\mathrm{qPCR}$ was repeated three times, and the results shown are representative, with triplicates for each sample

type sample was significantly higher than that in the mutant one (Fig. 3). ACVRL1/ALK1 expression was also decreased, which may be explained by a crosstalk between both genes, published before [24]. Therefore, these results represent in vivo confirmation of the deficient expression of Endoglin in the HHT patient related with the change (c.-58 G>A) in the promoter. Next, we decided to test whether the binding of a transcription factor could be prevented by changing $\mathrm{G}$ to $\mathrm{A}$.

\section{Changing $\mathrm{G}>\mathrm{A}$ in the promoter interferes with transcription factor binding}

The MatInspector program (Genomatix) (2005) [25] predicted that the change $(-58 \mathrm{G}>\mathrm{A})$ was in a Sp1/GC factor consensus that also overlapped also with SBE (Smad binding elements) and partially overlapped a core region for the core promoter element for RNA pol II (CPE) transcription for TATA-less promoters, in the case of Endoglin. The site where the mutation was placed and the putative binding places for these transcription factors is depicted in Fig. 4.
The next step was to synthesize a double-stranded oligonucleotide probe covering the region encompassing the mutation and then test whether we could detect DNA-protein complexes in a gel shift assay. As shown in Fig. 5, when the nuclear extract from endothelial cells (HMEC-1 cell line) was incubated with the doublestranded biotinylated oligonucleotide, in the presence of unspecific competitor poli (dI-dC), a retardation band could be detected (lane 2). However, the band was not visualized after the sample was incubated with a $100 x$ excess of the unlabeled double-stranded nucleotide (cold probe) (lane 3). When there was competition between the mutated oligonucleotide and the wild type nucleotide, the retarded band was not so efficiently decreased (lane 4). Therefore, there was a protein complex binding the region in which the mutation was placed, which, according to the predictions in Fig. 4, is a complex of the Sp1/GC-rich family of transcription factors. Therefore, the results suggest that the mutation (c.-58 G >A) in the proximal promoter of Endoglin precludes or disturbs Sp1 binding to initiate transcription. This explains why transcription is inefficient and Endoglin haploinsufficiency occurs.

\section{Discussion}

HHT is caused by mutations in the transforming growth factor-beta (TGF- $\beta$ ) signaling pathway genes $E N G$, $A C V R L 1 / A L K 1$, and SMAD4 [5-7], and the more recently identified $B M P 9$ [9].

Haploinsufficiency has been postulated to be the mechanism of pathogenesis leading to HHT. In this particular case, mutation (c.-58 G > A) in the promoter of Endoglin precluded Sp1 binding and the initialization of efficient transcription. Transcription proceeds normally only from the wild type allele. Therefore, the mutation described outlines a new way to generate Endoglin haploinsufficiency.

With the advent of next generation sequencing (NGS), a new era has begun in which HHT molecular diagnostics can be performed more quickly, easily, and inexpensively. McDonald and coworkers [15] have set up multi-gene NGS panels for the rapid molecular diagnosis of HHT.

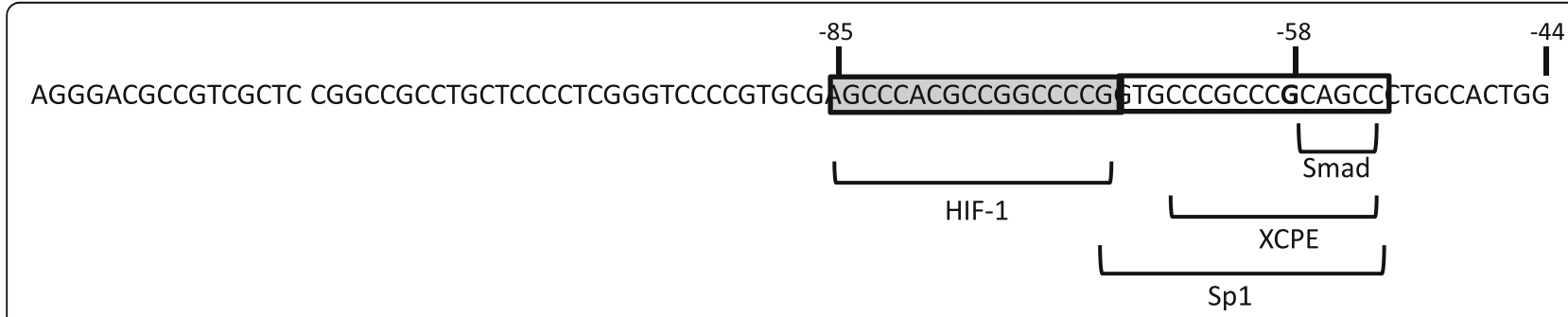

Fig. 4 Schematic representation of the proximal promoter region encompassing the $-58(G>A)$ site and the transcription factors binding to it, according to the Matlnspector program (Genomatix) 


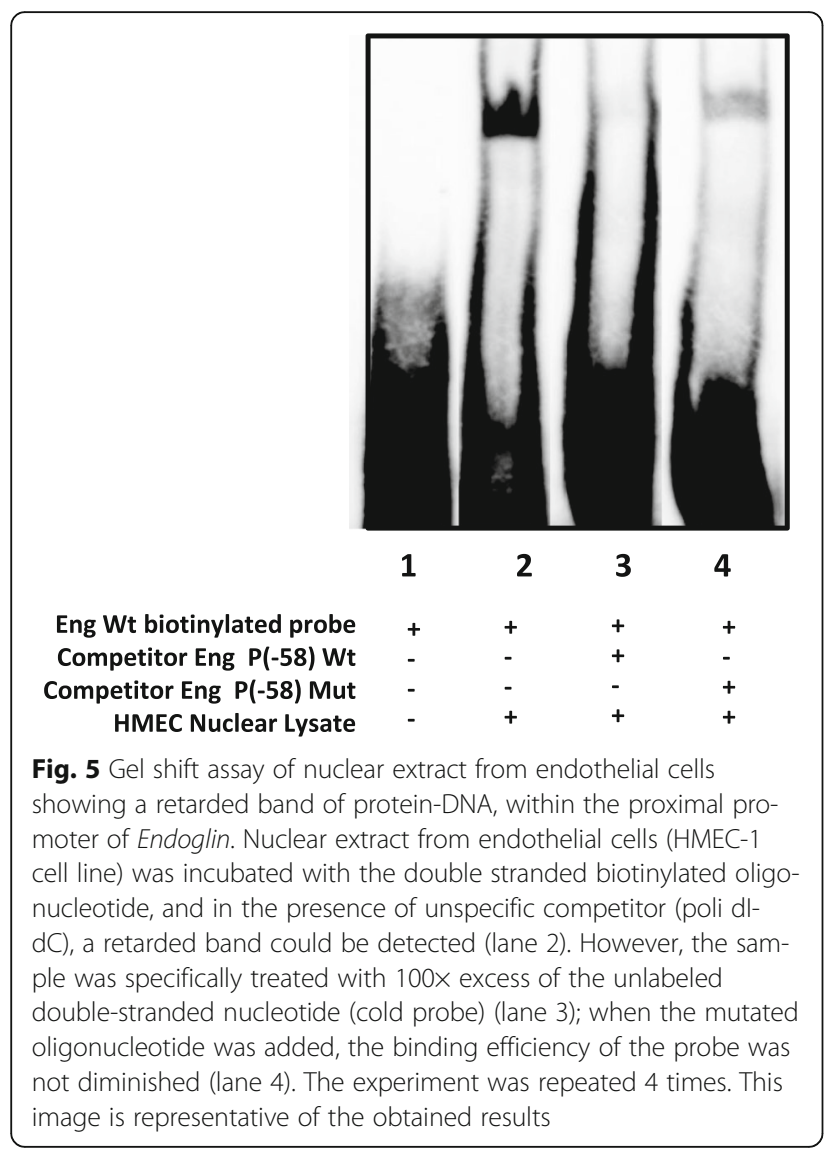

However, approximately 5-10\% of individuals clinically identified as having HHT, according to the clinical Curaçao criteria, currently have no known genetic cause [15]. Should we look for additional causative genes or genetic modifiers beyond those already described? Alternatively, are deep intronic variants or changes in the regulatory (promoter, enhancer) regions of the already known ENG, ACVRL1/ALK1, MADH4, and BMP9 genes responsible for HHT, which accounts for the percentage of genetically undiagnosed patients?

Current clinical testing protocols, including whole exome sequencing (WES), only involve exons and intronic boundaries. To cover regulatory and deep intronic regions, the advent of targeted whole gene capture of the relevant loci, including introns and UTRs, would be desirable in this scenario. This issue was supported by Marchuk, and the results of the Arup group can serve as an alternative to looking for new HHT genes [26].

Van Sant-Webb and colleagues demonstrated that some HHT patients with no known genetic cause may have a deleterious non-coding region variant in a known HHT gene [27].

One could imagine that including longer upstream regions of the promoters (primarily ENG and ACVRL1/ $A L K 1)$ and sequencing the introns would increase the feasibility to find variants affecting the splicing and regulation of the candidate genes, and the rate of genetic diagnosis would increase significantly. The importance of sequencing the entire ENG and ACVRL1/ALK1 (even $S M A D 4$ or BMP9) genes, depending on the clinical symptoms, is clear before looking for additional genes.

Thus, the results shown in the present paper constitute an example of the last statement.

Although there have been 2 previous reports of 3 variants affecting the 5'UTR region of ENG of Endoglin, two were pathogenic as a result of the generation of an alternative transcription start codon that was out of frame, without excluding transcription factor binding [19]. This is the first work showing that a change in the proximal promoter of Endoglin precludes Sp1 transcription factor binding around the -58 bp position in the minus strand. Sp1 was described as an essential factor for Endoglin basal transcription [23], in the absence of TATA box.

Altogether, this paper concludes that whole gene sequencing, not just coding regions, of ENG, ACVRL1/ $A L K 1$, and depending on the phenotype, even of Smad4 and $B M P 9$, may reveal that non-coding regions play a larger role in HHT disease pathogenesis, which may help to cover the full range of genetic diagnoses in clinically diagnosed patients.

\section{Conclusion}

This manuscript constitutes the first work, to the best of our knowledge, demonstrating a mutation in the proximal promoter of Endoglin that affects the transcriptional regulation of Endoglin, downregulating it and leading to likely HHT pathogenic manifestations. The change of a single nucleotide precludes the binding of $\mathrm{Sp} 1$, which is an essential factor for Endoglin basal transcription, around the -58 bp location in the minus strand.

Many HHT patients with unknown genetic profiles may have mutations located in the regulatory regions of either Endoglin or ACVRL1/ALK1. This work emphasizes the need for increased coverage by sequencing of non-coding regions in the relevant loci, uncovering regions that have not been observed in exome sequencing.

It is very likely that in HHT we do not need to look for more genes but should instead consider the entire genomic sequence of $A C V R L 1 / A C V R L 1 / A L K 1$ and $E N G$ to identify changes in non-coding regions that may affect transcription, splicing and even translation.

\section{Abbreviations}

ACVRL1/ACVRL1/ALK1: Activin Receptor Kinase Like type 1; ALK5: Activin Like kinase Type 5; AVM: Arterio-Venous Malformations; GDF: Growth and Differentiation Factors; HHT: Hereditary Hemorrhagic Telangiectasia; HMEC1: Human Microvasculature Endothelial Cells; JP: Juvenile Polyposis; MADH4/ SMAD4: Mothers Against Decapentaplegic; MLPA: Multiplex Ligation PCR Assisted; R-Smads: Receptor Smads; Sp1: Specific protein 1; TGF- 
$\beta$ : Transforming growth factor beta; TRRI/RII: Receptors type I and II of Transforming Growth Factor beta; UTR: Untranslated region

\section{Acknowledgments}

This study has been supported by grants from Ministerio de Economia y Competitividad of Spain (SAF2011-23475 and SAF2014-52374-R) to L.M. Botella and Centro de Investigación Biomedica en Red de Enfermedades Raras (CIBERER). CIBERER is an initiative of the Instituto de Salud Carlos III (ISCIII) of Spain. V. Albiñana is the recipient of a contract from the Spanish Alianza of VHL and the HHT Spanish Patient Association. L. Recio-Poveda is the recipient of a contract from the HHT Spanish Patient Association, and M.P. Zafra was funded by IdiPAZ from Fundación Mutua Madrileña (Spain).

\section{Funding}

This study has been supported by grants from Ministerio de Economia y Competitividad of Spain (SAF2011-23475 and SAF2014-52374-R) to L.M. Botella and Centro de Investigación Biomedica en Red de Enfermedades Raras (CIBERER).

\section{Availability of data and materials}

All available data have been presented in the main paper. Any additional details concerning the pathology of the disease are available by request.

\section{Author's contributions}

VA: Completed RNA extractions, aPCR, statistical analyses and designed figures of the manuscript. MPZ: Performed gel shift assays. JC: Performed in vitro mutagenesis and transfection experiments with cells. RZ: MD in contact with patients who made clinical diagnoses and followed up with patients. LRP: Technical assistance in all techniques, particularly DNA extraction and preparation for sequencing. LO and JP-P: DNA sequencing of ACVRL1/ALK1, ENG, and MLPA. Critical review of the manuscript. LMB: Planning, direction, writing the manuscript and responsible for the work. All authors read and approved the final manuscript.

\section{Competing interests}

The authors declare that they have no competing interest.

\section{Consent for publication}

"Not applicable" in this section.

\section{Ethics approval and consent to participate}

Informed consent was obtained from each patient. HHT diagnosis was based on the clinical Curaçao criteria (Shovlin et al., 2000). Each sample was anonymously treated and identified by a code number. Human blood samples and clinical data reported in this manuscript were obtained with the prior approval of the appropriate ethics committees of the CSIC for the research conducted in the Centro de Investigaciones Biológicas (CIB, Madrid), the CEIC (Clinical Research Ethics Committee) of the Cantabrian Health Service for patients attending the Hospital of Sierrallana (Torrelavega, Santander, Cantabria), and the Medical Genetics department of the Hospital Valdecilla (Santander, Cantabria). Research was carried out in compliance with the Helsinki Declaration (http://www.wma.net/en/30publications/ 10policies/b3/index.html), keeping the results strictly confidential, with numerical codes for patient identification. http://www.wma.net/en/ 30publications/10policies/b3/index.html.

\section{Author details \\ ${ }^{1}$ Centro de Investigaciones Biológicas, Consejo Superior de Investigaciones Científicas (CSIC), and Centro de Investigación Biomédica en Red de Enfermedades Raras (CIBERER), Ramiro de Maeztu 9, Madrid 28040, Spain. ${ }^{2}$ HHT Spanish Unit, Hospital Sierrallana and Centro de InvestigacionBiomedica en Red de Enfermedades Raras (CIBERER), Torrelavega, Santander, Spain. ${ }^{3}$ Secugen SL, Madrid, Spain.}

Received: 18 March 2016 Accepted: 9 February 2017 Published online: 23 February 2017

\section{References}

1. Geisthoff UW, Nguyen HL, Röth A, Seyfert U. How to manage patients with hereditary haemorrhagic telangiectasia. Br J Haematol. 2015;171:443-52. doi: 10.1111/bjh.13606. Review.
2. Shovlin CL. Hereditary haemorrhagic telangiectasia: pathophysiology, diagnosis and treatment. Blood Rev. 2010;24(6):203-19. doi:10.1016/j.blre.

3. Shovlin $\mathrm{CL}$, Guttmacher $\mathrm{AE}$, Buscarini $\mathrm{E}$, Faughnan $\mathrm{ME}$, Hyland $\mathrm{RH}$, Westermann CJ, Kjeldsen AD, Plauchu H. Diagnostic criteria for hereditary hemorrhagic telangiectasia (Rendu-Osler-Weber syndrome). Am J Med Genet. 2000:91:66-7.

4. Fernández-L A, Sanz-Rodriguez F, Blanco FJ, Bernabéu C, Botella LM. Hereditary hemorrhagic telangiectasia, a vascular dysplasia affecting the TGF-beta signaling pathway. Clin Med Res. 2006;4:66-78. Review.

5. McAllister KA, Grogg KM, Johnson DW, Gallione CJ, Baldwin MA, Jackson CE, Helmbold EA, Markel DS, McKinnon WC, Murrell J, et al. Endoglin, a TGFbeta binding protein of endothelial cells, is the gene for hereditary haemorrhagic telangiectasia type 1. Nat Genet. 1994;8:345-51.

6. Johnson DW, Berg JN, Gallione CJ, McAllister KA, Warner JP, Helmbold EA, Markel DS, Jackson CE, Porteous ME, Marchuk DA. A second locus for hereditary hemorrhagic telangiectasia maps to chromosome 12. Genome Res. 1995;5:21-8.

7. Gallione CJ, Repetto GM, Legius E, Rustgi AK, Schelley SL, Tejpar S, Mitchell G, Drouin E, Westermann CJ, Marchuk DA. A combined syndrome of juvenile polyposis and hereditary haemorrhagic telangiectasia associated with mutations in MADH4 (SMAD4). Lancet. 2004:363:852-9.

8. Cole SG, Begbie ME, Wallace GM, Shovlin CL. A new locus for hereditary haemorrhagic telangiectasia (HHT3) maps to chromosome 5. J Med Genet. 2005;42:577-82

9. Bayrak-Toydemir P, McDonald J, Akarsu N, Toydemir RM, Calderon F, Tuncali T, Tang W, Miller F, Mao R. A fourth locus for hereditary hemorrhagic telangiectasia maps to chromosome 7. Am J Med Genet. 2006;140:2155-62.

10. Wooderchak-Donahue WL, McDonald J, O'Fallon B, Upton PD, Li W, Roman BL, Young S, Plant P, Fülöp GT, Langa C, Morrell NW, Botella LM, Bernabeu C, Stevenson DA, Runo JR, Bayrak-Toydemir P. BMP9 mutations cause a vascularanomaly syndrome with phenotypic overlap with hereditary hemorrhagic telangiectasia. Am J Hum Genet. 2013;93:530-7. doi:10.1016/j.ajhg.

11. Goumans MJ, Valdimarsdottir $G$, Itoh $S$, Rosendahl A, Sideras $P$, ten Dijke P. Balancing the activation state of the endothelium via two distinct TGF-beta type I receptors. EMBO J. 2002;21:1743-53.

12. Lebrin $\mathrm{F}$, Goumans MJ, Jonker $\mathrm{L}$, Carvalho RL, Valdimarsdottir $\mathrm{G}$, Thorikay M, Mummery C, Arthur HM, ten Dijke P. Endoglin promotes endothelial cell proliferation and TGF-beta/ACVRL1/ALK1 signal transduction. EMBO J. 2004; 23:4018-28.

13. Blanco FJ, Santibanez JF, Guerrero-Esteo M, Langa C, Vary CP, Bernabeu C. Interaction and functional interplay between endoglin and ALK-1, two components of the endothelial transforming growth factor-beta receptor complex. J Cell Physiol. 2005;204:574-84.

14. Lesca G, Genin E, Blachier C, Olivieri C, Coulet F, Brunet G, Dupuis-Girod S, Buscarini E, Soubrier F, Calender A, Danesino C, Giraud S, et al. Hereditary hemorrhagic telangiectasia: evidence for regional founder effects of ACVRL1 mutations in French and Italian patients. Eur J Hum Genet. 2008;16:742-9.

15. McDonald J, Wooderchak-Donahue W, VanSant WC, Whitehead K, Stevenson DA, Bayrak-Toydemir P. Hereditary hemorrhagic telangiectasia: genetics and molecular diagnostics in a new era. Front Genet. 2015;6:1. doi: 10.3389/fgene.2015.00001. eCollection 2015. Review.

16. Abdalla SA, Letarte M. Hereditary haemorrhagic telangiectasia: current views on genetics and mechanisms of disease. J Med Genet. 2006;43:97-110. Review.

17. McDonald J, Damjanovich K, Millson A, Wooderchak W, Chibuk JM, Stevenson DA, Gedge F, Bayrak-Toydemir P. Molecular diagnosis in hereditary hemorrhagic telangiectasia: findings in a series tested simultaneously by sequencing and deletion/duplication analysis. Clin Genet. 2011;79:335-44.

18. Fontalba A, Fernández-Luna JL, Zarrabeitia R, Recio-Poveda L, Albiñana V Ojeda-Fernández ML, Bernabéu C, Alcaraz LA, Botella LM. Copy number variations in endoglin locus: mapping of large deletions in Spanish families with hereditary hemorrhagic telangiectasia type 1. BMC Med Genet. 2013: 14:121. doi:10.1186/1471-2350-14-121

19. Damjanovich K, Langa C, Blanco FJ, McDonald J, Botella LM, Bernabeu C, Wooderchak-Donahue W, Stevenson DA, Bayrak-Toydemir P. 5'UTR mutations of ENG cause hereditary hemorrhagic telangiectasia. Orphanet J Rare Dis. 2011;6:85

20. Yu Q, Shen XH, Li Y, Li RJ, Li J, Luo YY, Liu SF, Deng MY, Pei MF, Zhang GS. An intron mutation in the ACVRL1 may be associated with a transcriptional regulation defect in a Chinese family with hereditary hemorrhagic telangiectasia. PLoS One. 2013;8(2):e58031. 
21. Ríus C, Smith JD, Almendro N, Langa C, Botella LM, Marchuk DA, Vary CP, Bernabéu C. Cloning of the promoter region of human endoglin, the target gene for hereditary hemorrhagic telangiectasia type 1. Blood. 1998;92:4677-90.

22. Schouten JP, McElgunn CJ, Waaijer R, Zwijnenburg D, Diepvens F, Pals G. Relative quantification of 40 nucleic acid sequences by multiplex ligationdependent probe amplification. Nucleic Acids Res. 2002;30:e57.

23. Botella LM, Sánchez-Elsner T, Rius C, Corbí A, Bernabéu C. Identification of a critical Sp1 site within the endoglin promoter and its involvement in the transforming growth factor-beta stimulation. J Biol Chem. 2001;14:34486-94.

24. Sanz-Rodriguez F, Fernandez-L A, Zarrabeitia R, Perez-Molino A, Ramírez JR, Coto E, Bernabeu C, Botella LM. Mutation analysis in Spanish patients with hereditary hemorrhagic telangiectasia: deficient endoglin up-regulation in activated monocytes. Clin Chem. 2004;50(11):2003-11.

25. Cartharius K, Frech K, Grote K, Klocke B, Haltmeier M, Klingenhoff A, Frisch M, Bayerlein M, Werner T. MatInspector and beyond: promoter analysis based on transcription factor binding sites. Bioinformatics. 2005;21:2933-42.

26. Marchuk DA, Gallione CJ, Cirulli-Rodgers ET. HHT Mutation Discovery in the Era of Whole Exome/Genome Sequencing. $11^{\text {th }}$ International HHT Scientific Conference. Florida: Captiva; 2015

27. VanSant-Webb C, Wooderchak-Donahue W, McDonald J, Langa C, Benabeu C, Bayrak-Toydemir P. Uncovering the role of non-coding regions mutations in HHT. $11^{\text {th }}$ international HHT scientific conference. Florida: Captiva; 2015.

\section{Submit your next manuscript to BioMed Central and we will help you at every step:}

- We accept pre-submission inquiries

- Our selector tool helps you to find the most relevant journal

- We provide round the clock customer support

- Convenient online submission

- Thorough peer review

- Inclusion in PubMed and all major indexing services

- Maximum visibility for your research

Submit your manuscript at www.biomedcentral.com/submit 